\title{
Favelas do Rio de Janeiro: História e Direito
}

\section{Luis Claudio Palermo ${ }^{1}$}

1 Doutorando no Programa de Pós-Graduação em Ciências Sociais da Universidade do Estado do Rio de Janeiro (UERJ), Mestre em História Social pela UERJ e Graduado em História pela Universidade Gama Filho, Brasil. E-mail: luisclaudi072@gmail.com

Resenha de: GONÇALVES, Rafael Soares. Favelas do Rio de Janeiro: História e Direito. Rio de Janeiro: Pallas - Ed. PUC-Rio, 2013.

Há um conjunto de pesquisas que se tornou clássico no estudo sobre as favelas cariocas. Esses trabalhos cobrem uma gama de questões relevantes. 0 recém-lançado livro Favelas do Rio de Janeiro: História e Direito, de autoria de Rafael Soares Gonçalves (imagem a seguir), preenche uma lacuna historiográfica, na medida em que tem como objeto de estudo a construção histórico-sociológica das favelas fluminenses, a partir de seu aspecto jurídico. A abordagem do livro, entretanto, não se circunscreve ao estatuto jurídico das favelas na cidade. 0 autor parte dessa condição jurídica e, ao longo de todo 0

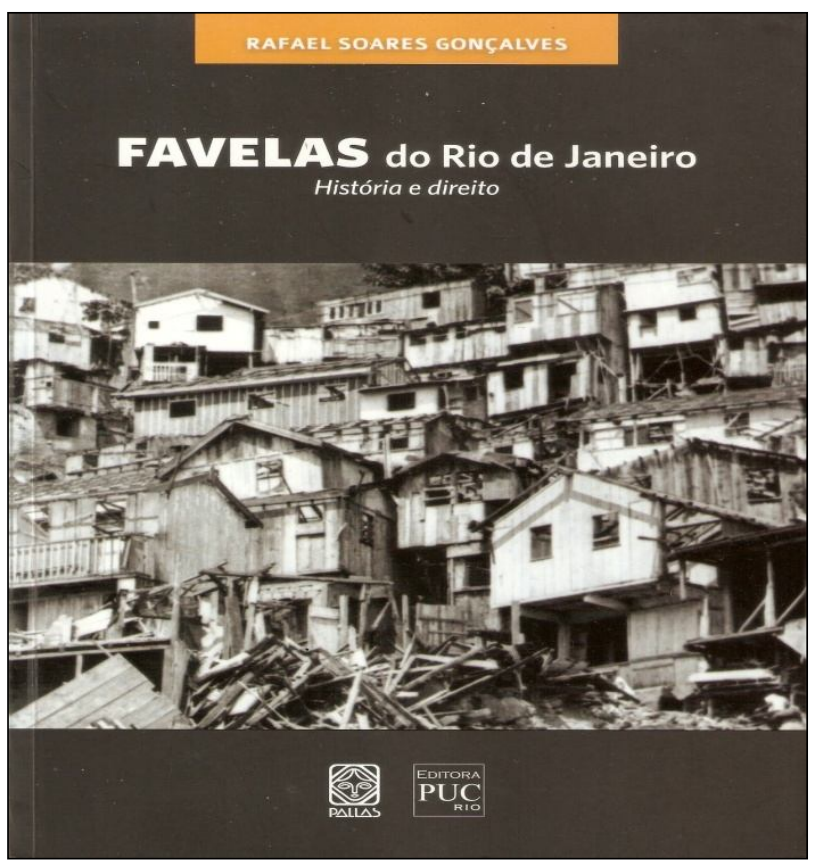
texto, coloca essa chave em diálogo com a conjuntura histórica e as dinâmicas sociológicas, a fim de vislumbrar não um lugar meramente jurídico para as favelas, mas sim entrever seus vínculos relacionais com a cidade.

A construção analítica que reveste a obra está fundamentada num corpus documental extenso e relevante, que parte das leis e decretos, passando por discursos da própria mídia ou de atores sociais que foram publicados na imprensa, chegando, por fim, até a utilização de debates legislativos, entre outras fontes importantes. Em adição, a relevante e extensa bibliografia é operacionalizada não apenas como uma referência estática; Gonçalves trava um diálogo profícuo com ela, o que permite compreender a erudição ativada e operacionalizada pelo autor para a composição desse trabalho de pesquisa.

0 aspecto jurídico relacionado às favelas não é trabalhado somente como um instrumento do poder para gerir o lugar das favelas na cidade, nem é invocado mera- 
mente no sentido de mostrar funcionalmente como o direito é um dispositivo que produz as favelas como margem do Estado (DAS; POOLE, 2004). Com isso, o aspecto jurídico é analiticamente utilizado na pesquisa para pensar em que medida as leis, decretos e outros dispositivos contribuem tanto para forjar um conceito para as favelas, como também se apresentam como reflexo das representações sócio-políticas desses lugares e de seus moradores. Logo, a ordem jurídica não é vista como "uma realidade hermética, apolítica" (GONÇALVES, p. 376, 2013), mas como um constructo que é capaz de reproduzir, reverberar ou, até mesmo, ocultar as assimetrias nas relações de força na sociedade, bem como, ao mesmo tempo, ser o meio de produção, reforço ou criação de diferenças ou desigualdades numa determinada sociedade. Nesse sentido, pensar a história do direito é se cercar de cuidados que alertam para a relação dialética que os dispositivos jurídicos têm com a sociedade.

O livro é composto de doze capítulos - além da introdução e epílogo - e está organizado em três partes que seguem a referência histórica marcada pela descontinuidade do conceito jurídico de favela, no Rio de Janeiro. Não se trata apenas de um modelo tradicional de organização de pesquisa e apresentação adequada de ideias. A divisão promovida pelo autor é parte intrínseca da construção de um ponto de vista cujo objetivo é promover um diálogo entre a condição jurídica e sociológica das favelas e as transformações políticas que marcam fases importantes da História do Brasil. Essa visão proporcionada pela obra em questão permite ao leitor compreender como há uma relação dialógica entre, por um lado, a busca por integração dos favelados na cidade e, por outro, a pressão dos fatores políticos estruturais.

Tendo em vista o fato de que a obra se propõe a apresentar a história da construção das favelas do Rio de Janeiro como uma categoria jurídica, a primeira parte, intitulada "A construção do conceito jurídico favela", aborda o surgimento desses lugares de moradia na cidade, no período que se inicia na transição do século XIX para 0 XX e vai até o fim do Estado Novo governado por Getúlio Vargas, em 1945. Nessa parte, o problema da moradia envolvido numa conjuntura de gradual crescimento do comércio e da urbanização é adotado como eixo central.

0 estabelecimento das primeiras favelas é compreendido, nesse período, não somente com base nas reformas urbanas promovidas pelo Estado, mas também são levadas em consideração as representações sociais dessas moradias populares que acabaram sendo tratadas de forma similar à política higienista realizada contra os cortiços. Nessa conjuntura, portanto, 0 autor mostra que as obras realizadas pelo prefeito Pereira Passos acabaram definindo zonas específicas para a cidade: o Centro para os negócios, a Zona Sul para os abastados e os subúrbios para a população pobre. A despeito disso, o livro ressalta que as favelas acompanharam a expansão do tecido urbano e se tornaram parte integrante desse processo, produzindo um desenho urbano diferente do que previa a normatividade contida nas propostas governamentais.

A presença dessas moradias nas áreas de negócios e nas regiões onde morava a 
população mais abastada motivou mudanças na forma de relação entre o poder central e esses lugares de moradia. Gonçalves mostra que a principal mudança se relacionava à postura político-jurídica do Estado, que passou a tratar esses aglomerados urbanos menos pelo ângulo da tolerância e mais pela perspectiva de um problema político de cunho urbano. Nas regiões suburbanas, no entanto, as favelas ainda eram toleradas.

Nessa primeira parte do livro é colocado em discussão, ainda, um dispositivo jurídico bastante importante para se pensar o lugar das favelas em face do desenvolvimento urbano e industrial. Trata-se do Código de Obras de 1937. Resultado, entre outros fatores, de um novo arranjo de poder após os anos 1930, o supracitado Código instaura uma nova relação desses locais de moradia com o governo, pois se trata da primeira definição jurídica oficial que caracteriza as favelas. 0 autor mostra o quão ambíguo foi o Código em apreço, na medida em que previa a extinção desses lugares de moradia, mas reconhecia, por outro lado, direitos específicos a esses moradores, 0 que era uma forma de confirmação jurídica da existência social e política das favelas no cenário urbano.

Em termos históricos, a segunda parte do livro, denominada "A (des)construção do conceito jurídico favela", é iniciada na segunda metade da década de 1940, fase que marca o início da democracia, bem como apresenta um desenvolvimento mais significativo dos processos de industrialização e urbanização. A partir dessas inflexões, 0 autor observa o crescimento significativo das favelas no tecido urbano, o que motivou sua tolerância funcional nas cidades.

Ora, se na fase anterior, tolerância significava - do ponto de vista do governo - ter paciência enquanto se buscava uma solução política que daria um fim efetivo às favelas, que representavam um problema de higiene e de falta de beleza na cidade, nesse momento histórico pós-1945, a tolerância a esses lugares de moradia estava ligada, segundo Gonçalves, à administração negociada do "problema" da favela (M ACHADO DA SILVA, p. 228, 2002). Nesse sentido, tolerar significava não abrir margem de possibilidade para a legalização desses lugares de moradia. Foi dessa forma que a representação social das favelas como lugares em que predominavam a ilegalidade foi paulatinamente sendo consolidada. Nesse período democrático, o autor nos mostra como a legislação reforçou o estatuto ilegal das favelas que havia sido definido pelo Código de Obras de 1937. Em outros termos, a tolerância às favelas agora significava não consolidá-las no tecido urbano, pois, ao manter sua condição de ilegalidade, poder-se-ia propor, a qualquer momento, a remoção de seus moradores para outros lugares.

A tolerância política das favelas e o objetivo de controlá-las podem ser identificados nas discussões concernentes ao papel das entidades religiosas que passaram a atuar sistematicamente nas favelas: Fundação Leão XIII e Cruzada São Sebastião. Ambas surgem nessa conjuntura em que as favelas ganham maior visibilidade política e na qual se pode identificar o crescimento da influência do Partido Comunista Brasilei- 
ro (PCB) nas favelas. Essa disputa ideológica entre direita e esquerda, numa conjuntura global de Guerra Fria, acabou contribuindo para dar forma à vida política e social voltada para os referidos lugares de moradia. Sintomaticamente, o livro nos mostra que os movimentos de base nas favelas, nesse período, estruturaram-se tanto a fim de fazer frente às ameaças de remoção, como também com o objetivo de lutar por melhorias locais.

Não menos importante, nesse cenário, é o destaque que é concedido no livro ao aumento das práticas clientelistas nas favelas cariocas. Longe de ser uma parceria bem sucedida em termos de atendimento aos interesses político, social e economicamente estruturais desses lugares de moradia, tais práticas sancionavam relações público-privadas que serviram mais para atomizar as demandas dos favelados do que como contribuição para estimular uma consciência política que os favorecesse. Assim, as reivindicações pautadas essencialmente pelo direito dos favelados na cidade perderam espaço para a lógica da concessão de benefícios individuais ou coletivo.

Encerrando essa segunda parte, é apresentada a (des)construção do conceito jurídico relacionado à favela, na medida em que a instauração da ditadura militar, com apoio de parcela da sociedade civil, acabou reconfigurando o papel dessas localidades na cidade. No plano estadual, Carlos Lacerda - então governador do Estado da Guanabara - , após a demissão de Arthur Rios da Coordenação de Serviço Social, estimulou a máquina pública a promover uma política de remoção e erradicação em massa das favelas. No plano federal, 0 autor argumenta que a relação das favelas com o Estado passou, nessa fase, a ser mais pautada por um discurso tecnicista do que pelo viés clientelista. Dessa forma, acionava-se uma estrutura jurídicoinstitucional que visava ensejar um modelo de ações sistemáticas no sentido da remoção dos favelados.

A parte derradeira do livro, que é denominada "A reconstrução do conceito jurídico favela", inicia-se com o processo de transição gradual do regime ditatorial para a democracia, bem como guarda relação com a fusão do Estado do Rio de Janeiro com - Estado da Guanabara (1975). Essa fase é marcada pela gradativa realização das propostas de urbanização das favelas. Assim, a partir da segunda metade da década de 1970, em vez da tolerância funcional na cidade, os favelados vão sendo inseridos, paulatinamente, nas pautas políticas com um sentido voltado para a urbanização.

Nessa conjuntura, a abertura política e a pauta dos direitos favoreceram as reivindicações das camadas sociais que estavam à margem, além de terem propiciado 0 surgimento de governos que se abriram a essas pautas. Em outros termos, com a participação ativa dos moradores de favelas na luta por direito à cidade, bem como de entidades que defendiam suas causas, o modelo urbanizador foi progressivamente ganhando força, em detrimento da tendência remocionista.

Cumpre registrar que o autor mostra que, em função do novo panorama político, uma nova questão passava a estar presente com maior vigor na agenda político-social do Rio de Janeiro: a regularização fundiária. A despeito dessas transformações políti- 
cas conjunturais que favoreceram a política de urbanização de favelas, a experiência fundiária acabou sistematicamente abandonada. Então, passou-se a "tolerar o aspecto informal da ocupação do solo, em vez de propor soluções duráveis e eficazes para o problema" (GONÇALVES, p. 268, 2013).

Após a Constituição de 1988, que foi um marco importante no campo jurídico, o autor aponta um conjunto de leis que foi promulgado contendo princípios jurídicos que concorreram para consolidar as favelas na cidade, estimulando o viés urbanizador, conforme exposto acima, mas sem lograr, por outro lado, êxito na integração plena dos moradores de favelas. 0 famoso projeto Favela-Bairro ilustra bem essa proporção entre o desenvolvimento da urbanização e da regularização fundiária. Se, por um lado, o projeto em apreço realizou melhorias para os moradores de favelas, por outro ângulo mostrou-se, segundo o autor, limitado no sentido da promoção de políticas sociais e da regularização fundiária.

0 livro acompanha também as transformações sociais nas favelas, a partir da década de 1990, apontando seu crescimento, o avanço da diversificação entre elas e 0 aumento da estratificação interna de cada localidade. Faz também o registro da presença mais ostensiva de traficantes de drogas nesses lugares de moradia. Uma das conclusões do autor acerca dessas transformações é que elas concorreram para impor dificuldades atinentes à discussão voltada para a regularização fundiária. Primeiro porque facilitou 0 acesso à moradia e fez prevalecer 0 interesse de alguns "latifundiários"; segundo porque a proximidade territorial com criminosos tornou os favelados mais estigmatizados, além de o controle territorial realizado pelos grupos de traficantes ter redundado no enfraquecimento da mobilização política coletiva desses moradores.

Outra inflexão destacada pelo autor que impacta na vida das favelas na cidade foi a mudança gradual do perfil da gestão política empregada na cidade do Rio de Janeiro. Desse modo, desde a década de 1990, o planejamento urbano vem postulando que as administrações das cidades devem ser pautadas pela noção de cidadeempresa, sobrevalorizando a tendência tecnicista. Nesse sentido, o último capítulo, intitulado "Ilegal, e daí?", impõe um cariz anticlimático à obra, pois mostra que, no século XXI, as favelas do Rio de Janeiro estão convivendo com o retorno do discurso remocionista. 0 título desse último capítulo é inspirado num conjunto de artigos que foram publicados no jornal 0 Globo cujo discurso centrava-se na justificativa do retorno das remoções, fundamentado na ilegalidade das construções nas favelas. Esses discursos emergiram por conta da descoberta de um prédio de onze andares na Rocinha. Ademais, de forma enviesada, os artigos também faziam menção ao agravamento da violência urbana. Portanto, partindo centralmente desses dois pontos - ilegalidade e violência urbana - , os artigos defendiam, segundo Gonçalves, que a remoção dos favelados e sua transferência para bairros distantes com rede de transporte e de serviços urbanos não se configurariam em questões problemas para a cidade.

Em função do que foi exposto, cumpre destacar que a obra em questão permite 
vislumbrar, pelo menos, duas questões importantes para discutir o lugar das favelas na cidade. A primeira relaciona-se à linha-mestra do trabalho de pesquisa de Gonçalves, que concerne à condição jurídico-normativa das favelas. A partir desse ponto de vista, conclui-se que as favelas, apesar de não terem conseguido a integração plena na cidade, logrou alguns resultados favoráveis a seus moradores, não tanto no tocante ao direito de acesso à regularização do solo, mas, especialmente, no que concerne à maior acesso aos equipamentos urbanos. Portanto, ao contrário do que muitos entendem, as favelas fazem parte da cidade, ainda que sua participação seja socialmente precária e politicamente subalterna; a segunda é fruto da visão dialética do autor, pois ele conseguiu visualizar, ainda que seu objeto de pesquisa seja constitutivamente de natureza normativa, que as conquistas conseguidas pelos moradores de favelas na cidade são resultantes também de sua luta política, o que abre caminho para pensar que as práticas de gestão estatal das favelas não são realizadas sem essa contrapartida. Ainda que seja assimétrica a relação de forças entre favelas e governo, em razão da condição de subalternidade histórica dos favelados, o autor mostra que as práticas jurídicas, na qualidade de um dispositivo que não é um "domínio autônomo do real" (M ACHADO DA SILVA, p. 11, 2013), dialogam, em alguma medida, com o poder de agência dos moradores.

\section{REFERÊNCIAS}

DAS, Veena; POOLE, Deborah (Ogs.). Anthropology in the margins of the state. Santa Fe: School of American Reserarch Press, 2004. GONÇALVES, Rafael Soares. FAVELAS do Rio de Janeiro: História e Direito. Rio de Janeiro: Pallas - Ed. PUC-Rio, 2013.

MACHADO DA SILVA, Luiz Antônio. "Prefácio à edição brasileira". In: GONÇALVES, Rafael Soares. Favelas do Rio de Janeiro: história e direito. Rio de Janeiro: Pallas - Ed. PUC-Rio, 2013.

. "A continuidade do 'problema favela'". In: OLIVEIRA, Lucia Lippi (Org.). Cidade: história e desafios. Rio de Janeiro: Editora FGV, 2002, pp. 220-237.

; LEITE, Márcia Pereira. "Violência, crime e polícia: o que os favelados dizem quando falam desse temas?". In: SILVA, Luiz Antonio Machado da (org.). Vida sob cerco: violência e rotina nas favelas do Rio de Janeiro. Rio de Janeiro: Nova Fronteira, 2008, pp. 47-76.

VALLADARES, Lícia do Prado. A invenção da favela: do mito de origem a favela.com. Rio de Janeiro: Editora FGV, 2005.

Resenha recebida em 10 de maio de 2015. Aprovado em 25 de outubro de 2016. 